\title{
PENGARUH VARIASI DIAMETER NOSEL TERHADAP TORSI DAN DAYA TURBIN AIR
}

\author{
Rosmiati ${ }^{1)}$, Ahmad Yani²) \\ Jurusan Teknik Mesin Universitas Trunajaya Bontang. ${ }^{1,2)}$ \\ Jl.Taekwondo RT.9 No. 55 Telp./Fax. (0548) 3035920 Bontang-Kaltim 75311 \\ Email: hanafi.rosmati@gmail.com¹),Email: yanibima@gmail.com²).
}

\begin{abstract}
Abstrak
Turbin air merupakan salah satu jenis mesin fluida dari kelompok mesin-mesin tenaga yang dapat merubah energy fluida menjadi energy mekanis berupa putaran poros turbin, kemudian energy mekanis pada putaran poros turbin tersebut digunakan untuk memutarkan generator dengan menggunakan air sebagai fluida kerja. Penelitian ini menggunakan turbin pelton yang bersudu sendok sayur dan bertujuan penelitian untuk mengetahui pangaruh variasi diameter nosel terhadap torsi dan daya turbin. Hasil penelitian menunjukan adanya pengaruh diameter nosel turbin terhadap torsi dan daya turbin yaitu torsi turbin maksimum terjadi pada diameter nosel $1 / 3$ inchi, kemudian torsi turbin kedua pada diameter nosel $1 / 2$ inchi, torsi turbin ketiga pada diameter nosel $3 / 4$ inchi, dan torsi turbin terendah terjadi pada diameter nosel 1 inchi. Metode penelitian yang digunakan adalah metode eksperimental nyata berskala laboratorium. Dari hasil penelitian turbin air dapat diambil kesimpulan bahwa torsi turbin dan daya turbin maksimum terjadi pada diameter nosel $1 / 3$ inchi dengan nilai torsi sebesar $0,645 \mathrm{Nm}$ dan daya turbin maksimum dengan nilai sebesar 5,966 Watt. Sedangkan torsi turbin dan daya turbin terendah terjadi pada diameter nosel 1 inchi dengan nilai torsi sebesar $0,165 \mathrm{Nm}$ dan nilai daya turbin sebesar 0,864 Watt.
\end{abstract}

Kata Kunci : Turbin air, diameter nosel, torsi dan daya turbin.

\section{Pendahuluan}

Indonesia memiliki energi air yang sangat melimpah dan tersebar diseluruh wilayahnya. Menurut Direktur Konstruksi dan Energi Terbarukan, PT. PLN, Indonesia memiliki potensi air sekitar 75.000-76.000 MW. Tetapi pemanfaatannya masih sekitar 3.783 MW untuk skala besar dan 220 MW untuk skala kecil [1].

Salah satu pembangkit listrik tenaga air yang digunakan untuk memanfaatkan tenaga air dan yang bisa dibuat adalah turbin air. Salah satu peralatan pokok dalam suatu pembangkitan listrik tenaga air ialah turbin air Pelton yang berfungsi mengubah Energi Potensial berupa energi kecepatan oleh Nozel menjadi Energi Mekanik berupa putaran pada poros turbin, untuk mendapatkan Energi Listrik maka poros turbin dikopel dengan generator [2].

Selama ini energi listrik disediakan oleh Perusahaan Listrik Negara (PLN), namun masih belum dirasakan secara merata oleh masyarakat terutama masyarakat pedesaan yang jauh dari jangkauan jaringan listrik [3]. Oleh karenanya diperlukan sumber energi alternatif yang yang dapat dimanfaatkan untuk pembangkit listrik dan tersedia di lingkungan pedesaan. Salah satu sumber energi alternatif tersebut adalah energy air [4]. 
Dengan adanya variasi diameter nosel maka didapatkan torsi turbin dan daya turbin yang maksimal, jadi setiap ukuran diameter dalam nosel maka torsi yang terjadi pada runner turbin juga akan berubah, begitu juga dengan daya turbin yang dihasilkan, hal ini disebabkan adanya perbedaan tekanan aliran air sehingga terjadi perbedaan kecepatan aliran air pada ujung nosel yang menumbuk sudu turbin tersebut.

\section{Tinjauan Pustaka}

Turbin air merupakan salah satu jenis mesin fluida dari kelompok mesin-mesin tenaga yang dapat merubah energy fluida menjadi energy mekanis berupa putaran poros turbin, kemudian energy mekanis pada putaran poros turbin tersebut digunakan untuk memutarkan generator dengan menggunakan air sebagai fluida kerja [5].

Berdasarkan perubahan energi turbin air dibedakan menjadi dua kelompok yaitu turbin impuls dan turbin reaksi.

\section{Turbin impuls}

Turbin impuls disebut juga dengan turbin air tekanan sama karena tekanan air yang keluar dari nossel tekanannya sama dengan tekanan atmosfir sekitarnya. Sehingga energi tempat dan energi tekanan yang dimiliki oleh aliran air dirubah semuanya menjadi energi kecepatan. Contoh dari turbin impuls ini adalah turbin pelton yang merupakan jenis turbin yang dibuat menjadi objek penelitian penulis.[6]

Turbin air pelton adalah sebuah alat berbentuk lingkaran yang dibangun di sungai yang mempunyai debit air kecil tetapi mempunyai head yang tinggi. Alat ini berputar pada sumbunya karena adanya dorongan aliran air melalui pipa pesat yang cukup cepat. Sejalan dengan berputarnya turbin, alat ini sekaligus mengambil air dari sungai dan ditampung dalam sebuah bak penampung, selanjutnya dialirkan melalui sebuah pipa pesat dan dikeluarkan melewati sebuah nossel [6].

\section{Turbin Reaksi}

Turbin Reaksi adalah turbin yang memanfaatkan seluruh energi (energi Potensial, kinetik dan tekanan) untuk menghasikan energi kinetik di sudu. Sudu pada turbin reaksi mempunyai profil khusus yang menyebabkan terjadinya penurunan tekanan air selama melalui sudu. Perbedaan tekanan ini memberikan gaya pada sudu sehingga runner (bagian turbin yang berputar) dapat berputar. Turbin yang bekerja berdasarkan prinsip ini dikelompokkan sebagai turbin reaksi. Runner turbin reaksi sepenuhnya tercelup dalam air dan berada dalam rumah turbin. pada pengujian turbin air hasil yang diharapkan adalah mendapatkan daya turbin [7].

Proses perhitungan dengan mengunakan persamaan berikut :[7]

Luas Penampang Saluran (A)

Persamaan untuk menghitung luas ujung saluran nosel yang menumbuk sudu turbin adalah :

$$
A=\frac{1}{4} \cdot \pi \cdot d^{2}
$$

Kapasitas Aliran (Q)

Untuk menghitung kapasitas aliran, digunakan persamaan :

$$
Q=A \cdot V
$$

Kecepatan Aliran (V)

Untuk menghitung kecepatan aliran, digunakan persamaan :

$$
V=\frac{Q}{A}
$$

Laju Massa Air yang Mengalir $(\dot{m})$

Massa aliran digunakan persamaan :

$$
\dot{m}=\rho \cdot Q
$$

Daya Air yang Mengalir $\left(\mathrm{P}_{\mathrm{a}}\right)$

Daya air dapat dihitung dengan mempergunakan persamaan : 


$$
P_{a}=\frac{1}{2} \rho \cdot A \cdot V^{3}
$$

Torsi Turbin (T)

Besarnya torsi dapat dihitung dengan persamaan :

$$
T=F \cdot R
$$

Kecepatan Anguler ( $\omega)$

Untuk kecepatan keliling turbin diperoleh dengan menghitung menggunakan persamaan :

$$
\omega=\frac{2 . \pi \cdot n}{60}
$$

Daya Turbin $\left(\mathrm{P}_{\mathrm{t}}\right)$

Daya turbin dihitung dengan persamaan :

$$
P_{t}=T . \omega
$$

\section{Metode Penelitian}

Dalam penelitian ini menggunakan skala laboratorium. Adapun metode yang akan digunakan dalam penelitian ini yaitu dengan menggunakan metode eksperimental nyata (true experimental research). Dalam hal ini perangkat penelitian dibuat sesuai dengan ukuran turbin yang akan diamati. Metode ini dilaksanakan dengan melakukan pengujian untuk mengetahui pengaruh variasi diameter nosel turbin terhadap torsi dan daya turbin air.

\section{Tempat dan Waktu Penelitian}

Penelitian ini dilaksanakan di Laboratorium Jurusan Teknik Mesin Fakultas Teknik Universitas Trunajaya Bontang dan waktu penelitian dilakukan pada Bulan April 2017.

\section{Variabel Penelitian}

Variabel yang digunakan pada penelitian ini terdiri dari; variabel bebas, variabel terikat dan variabel terkontrol.

1. Variabel Bebas

Variabel bebas adalah variabel yang ditentukan nilainya sebelum dilakukan penelitian terdiri dari : a. Variasi diameter nosel 1 inchi, 3/4 inchi, $1 / 2$ inchi, dan $1 / 3$ inchi.

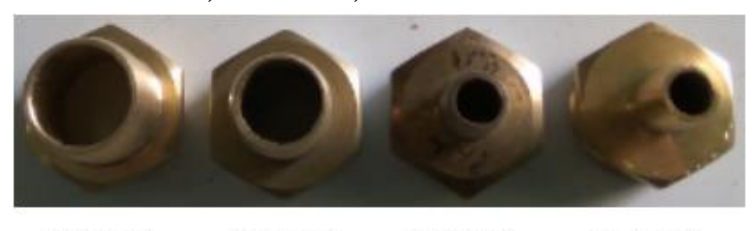

1 inchi $\quad 3 / 4$ inchi $\quad 1 / 2$ inchi $\quad 1 / 3$ inchi

Gambar 1. Variasi diameter nosel turbin

b. Debit air : $0,0005 \mathrm{~m}^{3} / \mathrm{s}$

c. Katup dalam keadaan buka penuh

1. Variabel Terikat

Variabel terikat adalah variabel yang nilainya sangat tergantung pada variabel bebas dan merupakan hasil dari penelitian. Variabel terikat yang diperoleh dalam penelitian ini adalah Torsi turbin dan daya turbin.

2. Variabel Terkontrol

Variabel terkontrol adalah Putaran turbin yang ditentukan untuk mengukur besaran gaya $(90,70,50,30$, dan $10 \mathrm{rpm})$ a. Bentuk sudu yaitu sudu sendok sayur

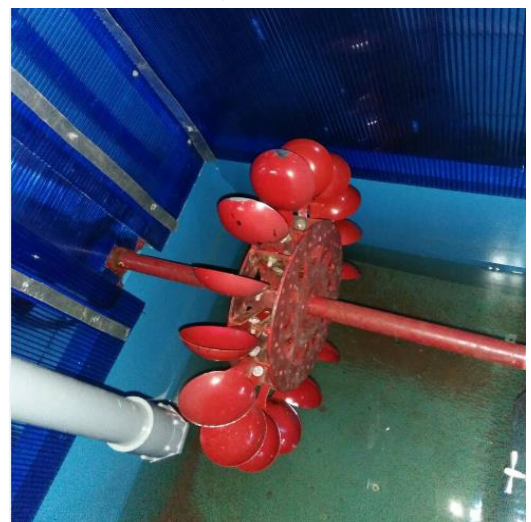

Gambar 2. Bentuk sudu sendok sayur

b. Jumlah sudu 16 buah.

c. Sudut sudu dikondisikan konstan pada posisi $90^{\circ}$.

d. Putaran turbin $350 \mathrm{rpm}, 300 \mathrm{rpm}, 250$ rpm, $200 \mathrm{rpm}, 150 \mathrm{rpm}, 100 \mathrm{rpm}, 50$ rpm dan $0 \mathrm{rpm}$.

\section{Prosedur Penelitian}

1. Memasang sudu turbin yang digunakan

2. Memasang nosel ukuran 1 inchi untuk pengambilan data pertama 
3. Pastikan semua kondisi alat dalam keadaan baik.

4. Tekan saklar untuk menghidupkan pompa air.

5. Pastikan posisi katup dalam keadaan membuka full.

6. Mengukur putaran poros turbin dengan alat ukur tachometer tanpa beban terlebih dahulu. Selanjutnya mengukur putaran poros turbin dengan beban yang diberikan secara pelan-pelan dengan cara memutar tuas penyetel beban gaya sampai memenuhi putaran yang divariasi dan mencatat nilai gaya pada alat ukur neraca pegas disetiap variasi pengukuran putaran turbin.

7. Mengulang langkah nomor dua sampai dengan enam pada variasi diameter nosel : $3 / 4$ inchi, $1 / 2$ inchi, dan $1 / 3$ inchi.

8. Mengolah data penelitian yang didapatkan.

9. Menganalisa data penelitian untuk mengetahui hubungan antara variabel yang telah ditentukan.

10. Menarik kesimpulan dari hasil penelitian yang dilakukan.

\section{Instalasi Alat Penelitian}

Pada penelitian ini alat pengujian yang digunakan adalah turbin air pelton yang dilakukan di laboratorium Teknik Mesin Universitas Trunajaya Bontang. Instalasi alat penelitian seperti ditunjukkan pada gambar 3.

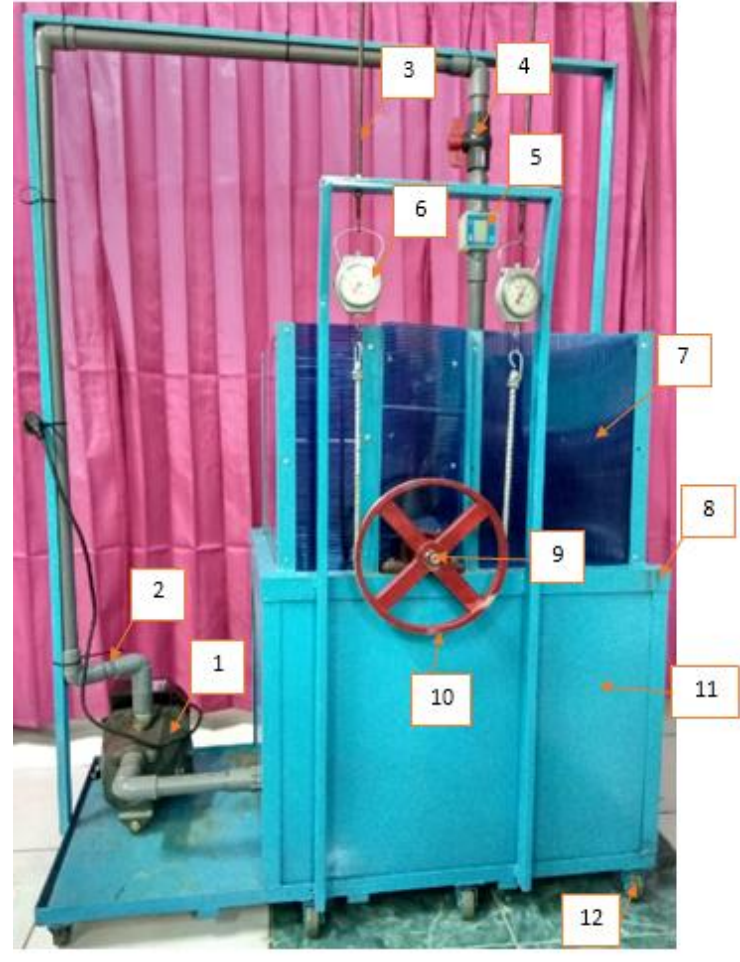

Gambar 3. Instalasi Penelitian.

Keterangan gambar instalasi penelitian turbin air :

1. Pompa air

2. Pipa PVC ukuran 1 inchi

3. Tuas Neraca Pegas

4. Katup

5. Flowmeter

6. Neraca Pegas

7. Rumah Turbin

8. Rangka Istalasi Turbin

9. Poros Turbin

10. Pully

11. Bak Penampung Air

12. Roda Istalasi Turbin

\section{Hasil dan Pembahasan}

Pengujian ini dilakukan dengan memvariasikan diameter nosel turbin untuk mendapatkan data putaran, data gaya, dan data ukuran pully yang digunakan dengan posisi komponen sebagaimana ditunjukan pada gambar 4. 


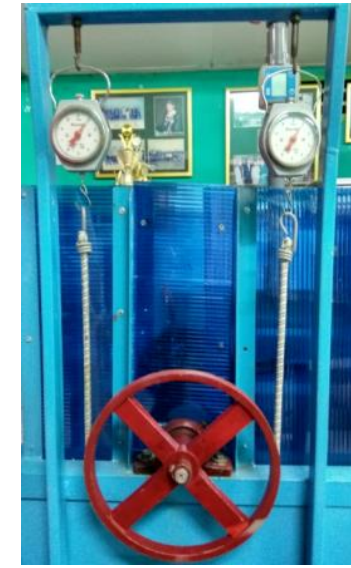

Gambar 4. Desain alat ukur Prony (torsi).

Dari penelitian yang dilakukan terhadap instalasi turbin dengan variasi ukuran diameter nosel turbin dimana nilai penunjukkan jarum skala putar dari kedua alat ukur neraca pegas merupakan jumlah gaya $\left(\sum F\right)$ seperti ditunjukkan pada gambar 4, sedangkan data putaran turbin (rpm) didapatkan dengan menggunakan alat ukur tachometer, dan jari - jari pully diukur menggunakan penggaris sehingga diperoleh data penelitian seperti ditunjukkan pada tabel 1 sampai tabel 4.

Tabel 1. Data pengujian nosel 1 inchi

\begin{tabular}{|c|c|c|}
\hline $\begin{array}{c}\text { Jari - jari pully } \\
\mathrm{r}(\mathrm{m})\end{array}$ & $\begin{array}{c}\text { Putaran } \\
\mathrm{n}(\mathrm{rpm})\end{array}$ & $\begin{array}{c}\text { Jumlah gaya } \\
\Sigma \mathrm{F}(\mathrm{Nm})\end{array}$ \\
\hline 0.15 & 109 & 0 \\
\hline 0.15 & 50 & 1,1 \\
\hline 0.15 & 0 & 1,4 \\
\hline
\end{tabular}

Tabel 2. Data pengujian nosel $3 / 4$ inchi

\begin{tabular}{|c|c|c|}
\hline $\begin{array}{c}\text { Jari - jari pully } \\
\mathrm{r}(\mathrm{m})\end{array}$ & $\begin{array}{c}\text { Putaran } \\
\mathrm{n}(\mathrm{rpm})\end{array}$ & $\begin{array}{c}\text { Jumlah gaya } \\
\mathrm{\Sigma F}(\mathrm{Nm})\end{array}$ \\
\hline 0.15 & 150 & 0.0 \\
\hline 0.15 & 100 & 0.9 \\
\hline 0.15 & 50 & 1.5 \\
\hline 0.15 & 0 & 2.3 \\
\hline
\end{tabular}

Tabel 3. Data pengujian nosel $1 \frac{1}{2}$ inchi

\begin{tabular}{|c|c|c|}
\hline $\begin{array}{c}\text { Jari - jari pully } \\
\mathrm{r}(\mathrm{m})\end{array}$ & $\begin{array}{c}\text { Putaran } \\
\mathrm{n}(\mathrm{rpm})\end{array}$ & $\begin{array}{c}\text { Jumlah gaya } \\
\Sigma \mathrm{F}(\mathrm{Nm})\end{array}$ \\
\hline 0.15 & 395 & 0.0 \\
\hline 0.15 & 350 & 0.5 \\
\hline 0.15 & 300 & 0.8 \\
\hline 0.15 & 250 & 1.2 \\
\hline 0.15 & 200 & 1.7 \\
\hline 0.15 & 150 & 2.0 \\
\hline 0.15 & 100 & 2.6 \\
\hline 0.15 & 50 & 2.8 \\
\hline 0.15 & 0 & 3.7 \\
\hline
\end{tabular}

Tabel 4. Data pengujian nosel $1 / 3$ inchi

\begin{tabular}{|c|c|c|}
\hline $\begin{array}{c}\text { Jari - jari pully } \\
\mathrm{r}(\mathrm{m})\end{array}$ & $\begin{array}{c}\text { Putaran } \\
\mathrm{n}(\mathrm{rpm})\end{array}$ & $\begin{array}{c}\text { Jumlah gaya } \\
\Sigma \mathrm{F}(\mathrm{Nm})\end{array}$ \\
\hline 0.15 & 316 & 0.0 \\
\hline 0.15 & 300 & 1.0 \\
\hline 0.15 & 250 & 1.2 \\
\hline 0.15 & 200 & 1.5 \\
\hline 0.15 & 150 & 1.9 \\
\hline 0.15 & 100 & 2.3 \\
\hline 0.15 & 50 & 3.1 \\
\hline 0.15 & 0 & 3.6 \\
\hline
\end{tabular}

Berdasarkan tabel 1 sampai tabel 4, data hasil pengujian bahwa gaya pengereman yang terjadi pada masing - masing ukuran nosel berbeda - beda walaupun putarannya dikondisikan sama.

\section{Hasil Pengolahan Data}

Dari data pengujian yang dilakukan tersebut kemudian dilakukan perhitungan untuk mendapatkan nilai torsi turbin dan 
daya turbin dan teknik analisa data menggunakan teknik deskriptif berdasarkan hasil penelitian yang dilakukan. Data yang diperoleh dari hasil pengujian kemudian dilakukan perhitungan menggunakan rumus terapan.

Tabel 5. Hasil pengolahan data torsi turbin pada semua ukuran diameter nosel

\begin{tabular}{|l|l|l|l|l|}
\hline \multirow{2}{*}{$\begin{array}{l}\text { Putaran, } \\
\text { n (rpm) }\end{array}$} & \multicolumn{4}{|l|}{ Torsi Turbin, T (Nm) } \\
\cline { 2 - 5 } & Nosel 1 inchi & $\begin{array}{l}\text { Nosel 3/4 } \\
\text { inchi }\end{array}$ & $\begin{array}{l}\text { Nosel 1/2 } \\
\text { inchi }\end{array}$ & $\begin{array}{l}\text { Nosel 1/3 } \\
\text { inchi }\end{array}$ \\
\hline 350 & & & 0.075 & 0.150 \\
\hline 300 & & & 0.120 & 0.180 \\
\hline 250 & & & 0.180 & 0.225 \\
\hline 200 & & & 0.255 & 0.285 \\
\hline 150 & & & 0.300 & 0.345 \\
\hline 100 & & 0.135 & 0.390 & 0.465 \\
\hline 50 & 0.165 & 0.225 & 0.420 & 0.540 \\
\hline 0 & 0.210 & 0.345 & 0.555 & 0.645 \\
\hline
\end{tabular}

\section{Pembahasan Hasil Penelitian}

Dari data tabel 5 kemudian dijadikan dalam bentuk grafik dan teknik analisa data menggunakan teknik deskriptif berdasarkan hasil eksperimen yang dilakukan di kampus Universitas Trunajaya Bontang, dalam pengolahan data dilakukan perhitungan untuk mendapatkan nilai torsi turbin. Pengolahan data bertujuan untuk mendapatkan grafik torsi turbin, pembuatan grafik dilakukan dengan menggunakan bantuan Microsoft Office Excel. Hubungan antara torsi dan putaran pada variasi diameter nosel turbin yang diteliti seperti ditunjukkan gambar 5 .

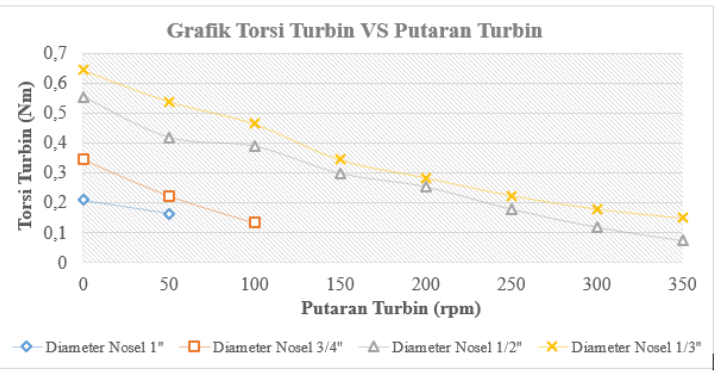

Gambar 5. Grafik hubungan torsi turbin terhadap putaran turbin.

Berdasarkan hasil pengolahan data dan gambar 5 yaitu grafik hubungan torsi turbin dan putaran turbin terhadap ukuran diameter nosel turbin terlihat bahwa dengan bertambahnya putaran turbin maka torsi turbin yang dihasilkan menurun secara proposional, hal ini terjadi karena pada proses pengambilan data putaran turbin dikondisikan nilainya berdasarkan gaya pengereman dan gaya pengereman inilah yang mempengaruhi nilai torsi turbin. Pada penelitian ini diberikan empat variasi diameter nosel yaitu diameter nosel 1 inchi, $3 / 4$ inchi, $1 / 2$ inchi, dan $1 / 3$ inchi.

Berdasarkan gambar 5 torsi turbin maksimum terjadi pada diameter nosel $1 / 3$ inchi, kemudian torsi turbin kedua pada diameter nosel $1 / 2$ inchi, torsi turbin ketiga pada diameter nosel $3 / 4$ inchi, dan torsi turbin terendah terjadi pada diameter nosel 1 inchi.

Pada diameter nosel 1 inchi didapat torsi turbin maksimum terjadi pada putaran terendah dengan nilai torsi turbin sebesar 0,210 Nm, sedangkan torsi turbin terendah terjadi pada putaran tinggi dengan nilai torsi turbin sebesar $0,165 \mathrm{Nm}$.

Pada diameter nosel $3 / 4$ inchi didapat torsi turbin maksimum terjadi pada putaran terendah dengan nilai torsi turbin sebesar 0,345 Nm, sedangkan torsi turbin terendah terjadi pada putaran tinggi dengan nilai torsi turbin sebesar 0,135 Nm.

Pada diameter nosel $1 / 2$ inchi didapat torsi turbin maksimum terjadi pada putaran terendah dengan nilai torsi turbin sebesar 0,555 Nm, sedangkan torsi turbin terendah terjadi pada putaran tinggi dengan nilai torsi turbin sebesar 0,075 Nm.

Pada diameter nosel $1 / 3$ inchi didapat torsi turbin maksimum terjadi pada putaran terendah dengan nilai torsi turbin sebesar $0,645 \mathrm{Nm}$, sedangkan torsi turbin terendah terjadi pada putaran tinggi dengan nilai torsi turbin sebesar $0,150 \mathrm{Nm}$. 
Tabel 6. Hasil pengolahan data daya turbin pada semua ukuran diameter nosel

\begin{tabular}{|c|c|c|c|c|}
\hline \multirow[b]{2}{*}{$\begin{array}{l}\text { Putaran, } \\
\mathrm{n}(\mathrm{rpm})\end{array}$} & \multicolumn{4}{|c|}{ Daya Turbin, Pt (Watt) } \\
\hline & $\begin{array}{l}\text { Nosel } 1 \\
\text { inchi }\end{array}$ & $\begin{array}{l}\text { Nosel } 3 / 4 \\
\text { inchi }\end{array}$ & $\begin{array}{l}\text { Nosel 1/2/2 } \\
\text { inchi }\end{array}$ & $\begin{array}{l}\text { Nosel 1/3 } \\
\text { inchi }\end{array}$ \\
\hline 350 & & & 2,748 & 5,495 \\
\hline 300 & & & 3,768 & 5,652 \\
\hline 250 & & & 4,710 & 5,888 \\
\hline 200 & & & 5,338 & 5,966 \\
\hline 150 & & & 4,710 & 5,417 \\
\hline 100 & & 1,413 & 4,082 & 4,867 \\
\hline 50 & 0,864 & 1,178 & 2,198 & 2,826 \\
\hline 0 & 0,000 & 0,000 & 0,000 & 0,000 \\
\hline
\end{tabular}

Hasil pengolahan data pengujian pada semua ukuran diameter nosel turbin untuk mendapatkan nilai daya turbin seperti ditunjukkan pada tabel 6, Dari data tabel 6 tersebut kemudian dijadikan dalam bentuk grafik daya turbin. Hubungan antara daya dan putaran pada variasi diameter nosel turbin seperti ditunjukkan gambar 6 .

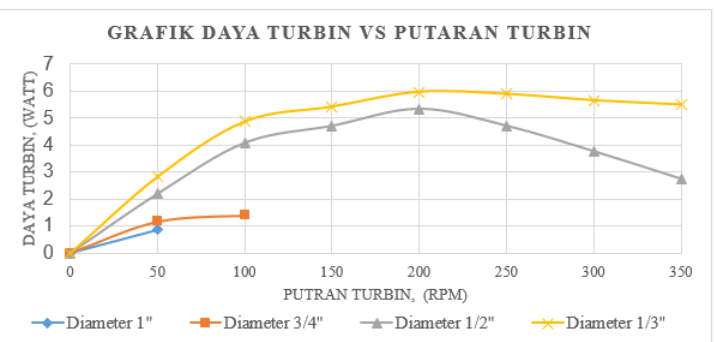

Gambar 6. Grafik hubungan daya turbin terhadap putaran turbin pada variasi bentuk sudu

Pada penelitian ini diberikan empat ukuran diameter nosel yaitu diameter nosel 1 inchi, $3 / 4$ inchi, $1 / 2$ inchi, dan $1 / 3$ inchi. Daya turbin sangat tergantung pada besarnya torsi dan kecepatan anguler, sedangkan besarnya kecepatan anguler dipengaruhi oleh putaran turbin yang didapatkan dengan menggunakan tachometer dan besarnya nilai torsi dipengaruhi oleh nilai gaya yang didapat dari neraca pegas. Berdasarkan gambar 6 daya turbin maksimum terjadi pada diameter nosel $1 / 3$ inchi, kemudian daya turbin kedua pada diameter nosel $1 / 2$ inchi, daya turbin ketiga terjadi pada diameter nosel 3/4 inchi, sedangkan daya turbin terendah terjadi pada diameter nosel 1 inchi.

Pada diameter nosel 1 inchi didapat daya turbin maksimum terjadi pada putaran 50 rpm dengan nilai daya turbin sebesar 0,864 Watt. Pada diameter nosel 1 inchi ini hanya satu nilai daya turbin dikarenakan putaran turbin sangat rendah akibat dari luasan penampang ujung nosel lebih besar didandingkan dengan ukuran diameter nosel yang lainya sehingga menyebabkan kecepatan aliran air yang keluar pada ujung nosel relatif rendah.

Pada diameter nosel $3 / 4$ inchi daya turbin maksimum terjadi pada putaran $100 \mathrm{rpm}$ dengan nilai daya turbin sebesar 1,413 Watt, sedangkan daya turbin terendah terjadi pada rpm 50 dengan nilai sebesar 1,178 Watt.

Pada diameter nosel $1 \frac{1}{2}$ inchi daya turbin maksimum terjadi pada putaran $200 \mathrm{rpm}$ dengan nilai daya turbin sebesar 5,338 Watt, sedangkan daya turbin terendah terjadi pada rpm 50 dengan nilai sebesar 2,198 Watt.

Pada diameter nosel $1 / 3$ inchi daya turbin maksimum terjadi pada putaran $200 \mathrm{rpm}$ dengan nilai daya turbin sebesar 5,966 Watt, sedangkan daya turbin terendah terjadi pada rpm 300 dengan nilai sebesar 0,471 Watt. Pada diameter nosel $1 / 3$ inchi mempunyai daya turbin tertinggi dari beberapa ukuran nosel yang lainya dikarenakan putaran turbin sangat tinggi akibat dari luasan penampang nosel lebih kecil sehingga menyebabkan kecepatan aliran air yang keluar pada ujung nosel sanggat tinggi.

\section{Kesimpulan}

Hasil penelitian menunjukan adanya pengaruh ukuran diameter nosel terhadap torsi dan daya turbin air pelton, sehingga dapat disimpulkan bahwa :

1. Torsi turbin maksimum terjadi pada diameter nosel $1 / 3$ inchi dengan nilai sebesar 0,645 Nm, kemudian torsi kedua 
pada diameter nosel $1 / 2$ inchi dengan nilai sebesar $0,555 \mathrm{Nm}$, torsi turbin ketiga terjadi pada diameter nosel $3 / 4$ inchi dengan nilai sebesar $0.345 \mathrm{Nm}$, dan torsi turbin terendah terjadi pada diameter nosel 1 inchi dengan nilai sebesar 0,165 $\mathrm{Nm}$.

2. Daya turbin maksimum terjadi pada diameter nosel $1 / 3$ inchi dengan nilai sebesar 5,966 Watt, kemudian daya turbin urutan kedua terjadi pada diameter nosel $1 / 2$ inchi dengan nilai sebesar 5,338 Watt, kemudian daya turbin urutan ketiga terjadi pada diameter nosel $3 / 4$ inchi dengan nilai sebesar 1,413 Watt, dan daya turbin terendah terjadi pada diameter nosel 1 inchi dengan nilai sebesar 0,864 Watt.

\section{Daftar Pustaka}

[1]. Direktorat Konstruksi dan Energi Baru Terbarukan, (2013). PT. PLN Persero.

[2]. Pamungkas Irwan N, Franciscus Asisi Injil P, Karwanto, Samodra Wasesa., (2013) Rancang Bangun Turbin Pelton Untuk Sistem Pembangkit Listrik Tenaga Mikro-Hidro Dengan Variasi Bentuk Sudu. Jurusan Teknik Mesin, Politeknik Negeri Semarang, Semarang

[3]. Bono dan Indarto. (2008).Karakteristik Daya Turbin Pelton Mikro Dengan Vari asi Bentuk Sudu", Seminar Nasional Aplikasi Sains Dan Teknologi, IST-AKPRIND, Yogyakarta.

[4]. Yani. A, Wahyudi. S. dan Denny. W (2012) "Pengaruh variasi panjang sudu mangkok terhadap kinerja turbin kinetik" Prosiding Seminar Nasional Science, Engineering and Technology, Brawijaya Malang.
[5]. Surbakti., R. O. (2009) perencanaan serta pembuatan prototype turbin air terapung bersudu lengkung dengan memanfaatkan kecepatan aliran air sungai. Skripsi teknik mesin universitas Sumatra utara. Medan

[6]. Thobari. A, Mustaqim, dan Wibowo H, (2013) "Analisa Pengaruh Sudut Keluar Sudu Terhadap Putaran Turbin Pelton" Jurnal ilmiah Faculty of Engineering, Universitas Pancasakti Tegal.

[7]. Yani. A, Mihdar dan Erianto. R (2016) "Pengaruh variasi bentuk sudu terhadap Kinerja Air turbin kinetik" ( Sebagai Pembangkit Listrik Daerah Pedesaan) Jurnal Turbo. Jurusan Teknik Mesin Fakultas Teknik Universitas Trunajaya Bontang - Kaltim. 